\title{
Primary Prevention of Alzheimer's Disease in Developing Countries
}

\author{
Anjana Rao Kavoor ${ }^{1}$, Sayantanava Mitra ${ }^{2}$, Tathagata Mahintamani ${ }^{3}$, Seshadri Sekhar Chatterjee ${ }^{4}$ \\ ${ }^{1}$ Department of Psychiatry, Institute of Mental Health and Hospital, ${ }^{2}$ Department of Psychiatry, Sarojini Naidu Medical College, Agra, \\ ${ }^{3}$ Department of Psychiatry, Central Institute of Psychiatry, Ranchi, ${ }^{4}$ Department of Psychiatry, Medical College, Kolkata, India
}

\section{TO THE EDITOR}

The "use it or lose it" theory of brain proposes that an enriched environment, a cognitively active life-style, and an exploratory rather than "indoor" exercise schedule can prevent or postpone dementia, ${ }^{1)}$ much like with a muscle. Enhancement of hippocampal volume; continued cellular proliferation, differentiation, survival and integration into circuits involving the hippocampus ${ }^{2}$ have all been reported with adoption of these methods.

Recently, it has been reported that low educational achievement has the highest estimated population-attributable risk (PAR; 19.1\%, 95\% confidence interval 12.3-25.6) worldwide in terms of developing Alzheimer's dementia (AD); while physical inactivity contributed highest in this regard in developed world. ${ }^{3)}$ PAR, in this report, has been calculated through meta-analysis of existing data for seven modifiable factors. As PAR measures the proportion of cases that would not occur in a population if concerned factor was eliminated, this revelation is of seminal importance. It is, therefore, implied that improving access to education and physical exercise could help the world avoid an epidemic of AD. ${ }^{3)}$

"Developing nations" like India face certain unique problems in this regard. They have to deal with widely prevalent poverty, which ensures that the population maintains dismal rates of adult literacy and conditions of general deprivation at-large. In India, for example, adult literacy rate was $62.8 \%$ during $2008-2012 .{ }^{4)}$ Since education is one of the cheapest and most generalizable methods for cognitive stimulation, approximately $37 \%$ of the adult population in this country might therefore be denied of their chances at stimulating their brains through cognitive

Received: April 16, 2015 / Accepted: April 30, 2015

Address for correspondence: Sayantanava Mitra, MD Department of Psychiatry, Sarojini Naidu Medical College, Mahatma Gandhi Rd, Raja Mandi Crossing, Bagh Muzaffar Khan, Shahganj, Agra, Uttar Pradesh 282002, India

Tel: +91-8298187766

E-mail: sayantanava@gmail.com exercises. At the same time, a fast incursion of sedentary lifestyle into traditional Indian society and associated physical inactivity might propagate obesity, increase metabolic risk factors ${ }^{5)}$ and expose the population to chances of developing AD.

Thus, with these two socio-economically opposing but physiologically complementary ultra-high PAR clusters at work; what are the chances that an AD epidemic could be avoided in the developing world in near future? India, in 2030, is expected to have its older population share more than $45 \%$ of the healthcare-related burden; and by 2045 , proportion of adults above 60 years might exceed those between $0-14 .{ }^{6)}$ In this age-group, associated urbanization is also expected to increase physical inactivity, while unequal distribution of wealth might still maintain poverty and keep cognitive stimulations at bay. Therefore, while a reduction in prevalence of these risk factors could predictably reduce the prevalence of $\mathrm{AD} ;{ }^{3}$ it would require massive undertakings by all stakeholders (governments and private players) in order to realize this dream. We believe that a concerted effort at alleviating poverty, improving access to quality education and lifestyle modification might enable us in achieving a better old age for the rapidly aging population of the developing world.

\section{REFERENCES}

1. Horne J. Exercise benefits for the aging brain depend on the accompanying cognitive load: insights from sleep electroencephalogram. Sleep Med 2013;14:1208-1213.

2. Shors TJ, Anderson ML, Curlik DM 2nd, Nokia MS. Use it or lose it: how neurogenesis keeps the brain fit for learning. Behav Brain Res 2012;227:450-458.

3. Norton S, Matthews FE, Barnes DE, Yaffe K, Brayne C. Potential for primary prevention of Alzheimer's disease: an analysis of population-based data. Lancet Neurol 2014;13:788-794.

4. UNICEF. Statistics of India [cited 2014 Aug 10]. Available from http://www.unicef.org/infobycountry/india_statistics.html

5. Kalra S, Unnikrishnan AG. Obesity in India: The weight of the nation. J Med Nutr Nutraceut 2012;1:37-41.

6. Chatterji S, Kowal P, Mathers C, Naidoo N, Verdes E, Smith $\mathrm{JP}$, et al. The health of aging populations in China and India. Health Aff (Millwood) 2008;27:1052-1063.

(a) This is an Open-Access article distributed under the terms of the Creative Commons Attribution Non-Commercial License (http://creativecommons.org/licenses/by-nc/4.0) which permits unrestricted non-commercial use, distribution, and reproduction in any medium, provided the original work is properly cited. 